\title{
An Analytical Study of the Strategies Used in Translating Trump's Tweets into Arabic
}

\author{
Mohammed Juma Zagood \\ Department of Translation Studies \\ College of Humanities and Social Sciences, UAE University \\ Al Ain, UAE
}

\begin{abstract}
It is increasingly interesting that one of the new focuses of translation studies is the translatability of the short posts on social media. Research in translating social media posts has recently received a greater attention among translation studies specialists. This paper looks firstly at Twitter as a growing social media networking and its language and, secondly, shedding some light on translation strategies used in translating English tweets into Arabic. Posts on Twitter, 'tweets,' by well-known figures are followed, translated, and reposted in other languages every day. Strategies used by Arab translators vary depending on the importance of the tweet as well as the ideology of the translator and the institutions they work for. This paper, therefore, investigates the translation strategies adopted by the Arab online news agencies, mentioned later, on their web pages in translating some tweets posted by the American President, Donald Trump in his first month of presidency. The analysis draws on Vinay and Darbelnet's (1958/1995) model and Nida's (1964) translation strategies.
\end{abstract}

Keywords: Online news, social media, translation strategies, translation model, Twitter

Cites as: Zagood, M. Z (2019). An Analytical Study of the Strategies Used in Translating Trump's Tweets into Arabic. Arab World English Journal for Translation \& Literary Studies, 3 (1) 22-34 . DOI: http://dx.doi.org/10.24093/awejtls/vol3no1.2 